\title{
Alat Monitoring Infus Set pada Pasien Rawat Inap Berbasis Mikrokontroler ATmega 8535
}

\author{
DECY NATALIANA ${ }^{1}$, NANDANG TARYANA ${ }^{2}$, EGI RIANDITA ${ }^{3}$
}

\author{
1,2,3Teknik Elektro Institut Teknologi Nasional (ITENAS) Bandung \\ Email : decyhari@gmail.com
}

\begin{abstract}
ABSTRAK
Metode yang digunakan untuk mengetahui volume cairan Infus adalah dengan cara mendeteksi tetesan yang berada pada chamber Infus. Tetesan dideteksi oleh sensor cahaya yaitu LED infra merah dan photodioda. Sinyal tegangan dari sensor dikondisikan dengan IC komparator LM339 . Mikrokontroler ATmega 8535 digunakan sebagai pengolah data I/O dari komparator sehingga informasi dari parameter yang dimonitor dapat ditampilkan pada LED dan LCD serta bunyi buzzer. Tegangan keluaran sensor infra merah saat mendeteksi tetesan adalah sebesar 1,02 $\mathrm{V}$ sedangkan saat tidak mendeteksi tetesan tegangan keluaran sebesar $180 \mathrm{mV}$. Parameter yang dapat dideteksi dari alat ini diantaranya jumlah tetesan per menit dengan maksimal jumlah tetes / menit yang dideteksi sebesar 255 tetes, peringatan bila tetesan tidak terdeteksi selama 10 detik dan peringatan bila cairan Infus akan habis ( $\pm 50 \mathrm{ml})$. Suara yang dihasilkan buzzer masih terdengar jelas dan tidak berbahaya bagi pendengaran perawat berdasarkan nilai ambang batas tingkat kebisingan meskipun keadaan di ruangan perawat dalam kondisi ramai.
\end{abstract}

Kata kunci: Infus set, intravena, photodioda, infra merah, mikrokontroler ATmega 8535, Infus.

\begin{abstract}
The method used to know the volume of Infusion fluid is detecting droplets that are on Infusion chamber. The droplets are detected by the light sensors is infrared LED and photodiode. The voltage signal from the sensor is conditioned by the digital comparator IC LM339. ATmega microcontroller 8535 is used as a data processor of the comparator output so that information from the monitored parameters can be displayed on the $L C D$ and $L E D$ and buzzer flame. The output voltage when infrared sensors detect a drop is $1.02 \mathrm{~V}$, while sensor does not detect a drop the output voltage drops is $180 \mathrm{mV}$. Parameters that can be detected from these tool include the number of drops per minute with a maximum number of drops / min was detected at 255 drops, a warning when the droplets are not detected for 10 seconds and a warning when Infuse fluids will run out ( $\pm 50 \mathrm{ml})$. Buzzer's sound still clearly audible and not dangerous for nurse's hearing based on noise level threshold value though the situation in the nurse's room in crowded conditions.
\end{abstract}

Keywords: Infusion sets, intravenous, photodioda, infra red, microcontroller, Infusion. 


\section{PENDAHULUAN}

Perkembangan teknologi elektronika dapat diaplikasikan di berbagai bidang dan akan sangat bermanfaat bila peralatan medis didukung dengan sistem elektronik. Peralatan medis yang dilengkapi sistem elektronik dapat lebih memperhitungkan kepresisian dan ketepatan. Hal ini berkaitan erat dengan pemanfaatannya pada bidang kesehatan yang dalam penanganannya sangat membutuhkan kepresisisan dan ketepatan sebaliknya bila penanganan yang dilakukan terdapat kesalahan maka akibatnya akan fatal bahkan dapat menyebabkan kematian. Pasien yang dirujuk untuk menjalani perawatan di rumah sakit mayoritas diberikan terapi infus intravena. Mulai dari pasien dengan kondisi yang kritis maupun pasien yang sedang menjalani masa pemulihan. Pemberian cairan infus pada pasien mempunyai suatu prosedural baku yang harus dipenuhi oleh dokter maupun perawat. Oleh karena itu, terapi infus intravena atau pemberian cairan ke dalam tubuh pasien memerlukan tindakan yang tepat mulai dari pasien mendapatkan infus sampai pasien tersebut pulih dan tidak memerlukan lagi asupan cairan infus. Penggunaan infus set konvensional yang digunakan sebenarnya tidak begitu bermasalah bila pasien dapat dikontrol dan diawasi secara periodik dalam waktu yang singkat oleh perawat. Namun hal ini seringkali menimbulkan masalah dikarenakan terdapat beberapa faktor seperti kurangnya sumber daya manusia di rumah sakit, kelalaian dari perawat, bahkan tindakan dari pasien itu sendiri.

Jati Fallat pernah merealisasikan alat monitoring infus menggunakan metoda pendeteksian cairan infus dari berat infus yang dihubungkan dengan sebuah pegas. Alat ini mempunyai resolusi yang kecil karena sistem ini menggunakan metoda perubahan resistansi dari potensiometer geser. Selain itu mekanik alat ini cukup sulit dan mempunyai ketahanan yang kurang baik karena infus dideteksi dari berat botol infus dengan menggunakan pegas dan potensiometer geser. (Falat, 2006)

Kasus fatal mengenai kesalahan penanganan pemberian infus intravena pada pasien adalah seorang bayi yang meninggal dikarenakan perawat terlambat untuk mengganti cairan infus sang bayi. Sungguh ironis sekali bila hal tersebut terjadi berulang (Tim Poskota, 2011)

Abdy Muslim pernah merealisasikan dan merancang sistem monitoring cairan infus secara terpusat yang dapat mengontrol laju cairan infus pasien berbasis mikrokontroler AtMega8535 dengan metode pengontrolan proposional-derivatif dan dapat memberikan informasi mengenai kondisi cairan infus pasien aktual kepada petugas medik secara terpusat menggunakan Radio frekuensi YS1020UB sebagai sarana komunikasi antara mikrokontroler dengan komputer. (Muslim, 2012)

Annisa Dwi Astuti pernah melakukan penelitian untuk penggunaan alat Infusion pump dilengkapi dengan drop sensor sebagai pengendali tetesan infus yang masuk ke dalam tubuh pasien, sehingga jumlah cairan infus yang diberikan sesuai dengan yang dibutuhkan pasien.

(Astuti, 2012)

Dengan melihat kondisi di atas, maka pada penelitian ini dilakukan suatu perancangan dan realisasi alat Monitoring Infus Set pada pasien rawat inap berbasis mikrokontroler ATmega 8535. Penelitian ini bertujuan untuk memberikan peringatan apabila terjadi tetesan terhenti dan cairan infus akan habis ( $\pm 50 \mathrm{ml}$ ) ke ruangan perawat berupa LED indikator dan buzzer serta menampilkan jumlah tetesan secara real time. 


\section{PERANCANGAN DAN REALISASI}

\subsection{Perancangan Sistem}

Perancangan sistem yang dijadikan penelitian memiliki beberapa langkah di dalam penyelesaiannya. Desain dari miniatur yang dirancang diperlukan agar sistem yang akan diimplementasikan tidak keluar dari tujuan awal. Terdapat dua buah ruangan dimana ruangan I merupakan ruang pasien. Pada ruangan pasien terdiri dari sensor optik (pendeteksi tetesan), komparator, keypad, LED indikator tetesan, LCD dan catu daya. Ruangan II adalah ruangan perawat. Pada ruangan perawat (ruang monitoring) terdiri dari LED indikator tetesan terhenti, LED indikator cairan infus akan habis ( $\pm 50 \mathrm{ml}$ ) dan buzzer seperti yang terlihat pada Gambar 1.



Gambar 1. Desain Awal dari Alat Monitoring Infus Set yang Dirancang

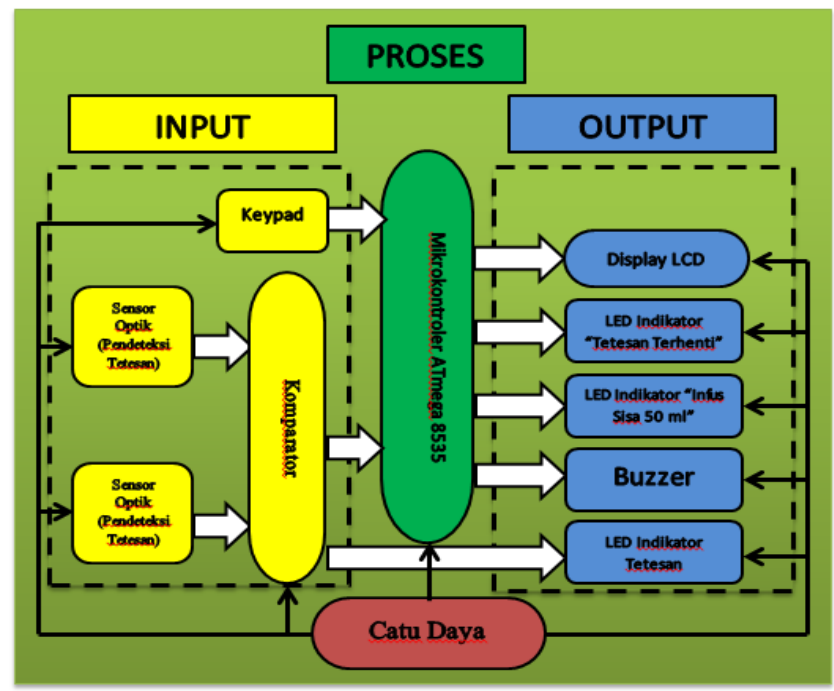

Gambar 2. Diagram Blok Alat Monitoring Infus Set 


\subsubsection{Input}

Pada bagian input sistem ini terdiri dari :

1. Sensor pendeteksi tetesan I dan II

Sensor ini digunakan untuk mendeteksi tetesan cairan infus pada chamber infus I dan II.

2. Komparator

Komparator ini digunakan untuk membandingkan tegangan input dengan tegangan referensi, saat ada tetesan maka komparator bernilai $\pm 5 \vee$ (logik 1 ) dan saat tidak ada tetesan maka komparator bernilai $0 \mathrm{~V}$ (logik 0 ).

3. Keypad

Keypad digunakan untuk memulai proses alat Monitoring Infus Set (start), memasukan data volume infus dan menghentikan proses alat Monitoring Infus Set (stop).

\subsubsection{Proses}

Secara diagram blok alat pada bagian proses hanya terdapat mikrokontroler saja yang nantinya akan mengendalikan seluruh proses pada alat monitoring infus ini.

\subsubsection{Output}

Pada bagian output sistem ini terdiri dari :

1. LCD (Liquid Crystal Display)

Menampilkan jumlah tetesan sebenarnya secara real time.

2. LED (Light Emitting Diode) Indikator

a. LED-1 dan LED-2 berfungsi sebagai indikator adanya tetesan cairan infus pada chamber infus I dan infus II.

b. LED indikator hijau I dan LED indikator hijau II berfungsi sebagai indikator apabila tetesan terhenti pada infus I dan infus II.

c. LED indikator kuning I dan LED indikator kuning II berfungsi sebagai indikator apabila cairan infus akan habis (sisa cairan infus $\pm 50 \mathrm{ml}$ ).

3. Buzzer I dan Buzzer II

Berfungsi untuk memberi peringatan berupa suara apabila terjadi tetesan terhenti dan cairan infus akan habis (cairan infus sisa $50 \mathrm{ml}$ ) pada infus I dan infus II.

\subsection{Spesifikasi Sistem}

Spesifikasi sistem yang diharapkan pada perancangan dan realisasi Tugas Akhir ini harus mampu melakukan beberapa proses yaitu :

1. Mampu mendeteksi tetesan cairan infus pada chamber infus.

2. Mampu menampilkan jumlah tetesan sebenarnya secara real time.

3. Mampu memberi informasi berupa tidak adanya tetesan dan tetesan terhenti dalam bentuk lampu indikator yang padam dan buzzer yang aktif.

4. Mampu memberi informasi berupa cairan infus akan habis (sisa cairan $\pm 50 \mathrm{ml}$ ) dalam bentuk lampu indikator yang padam dan buzzer yang aktif.

\subsection{Realisasi Perangkat Keras}

Perancangan perangkat keras (Hardware) alat Monitoring Infus Set pada pasien rawat inap dibangun dengan mengintegrasikan beberapa subsistem dengan spesifikasi yang telah ditentukan dari awal.

Perancangan perangkat keras pada alat ini terdiri dari beberapa blok rangkaian,diantaranya :

1. Perancangan Rangkaian Komparator dan Sensor

2. Perancangan Rangkaian Pengendali

3. Perancangan Rangkaian driver LCD 


\section{Rangkaian Komparator dan Sensor}

Pada rangkaian komparator ini mendapat input dari dua buah sensor pendeteksi tetesan. Sedangkan untuk output dari rangkaian komparator nya menuju ke dua buah LED indikator tetesan dan mikrokontroler yang dapat dilihat pada Gambar 3.

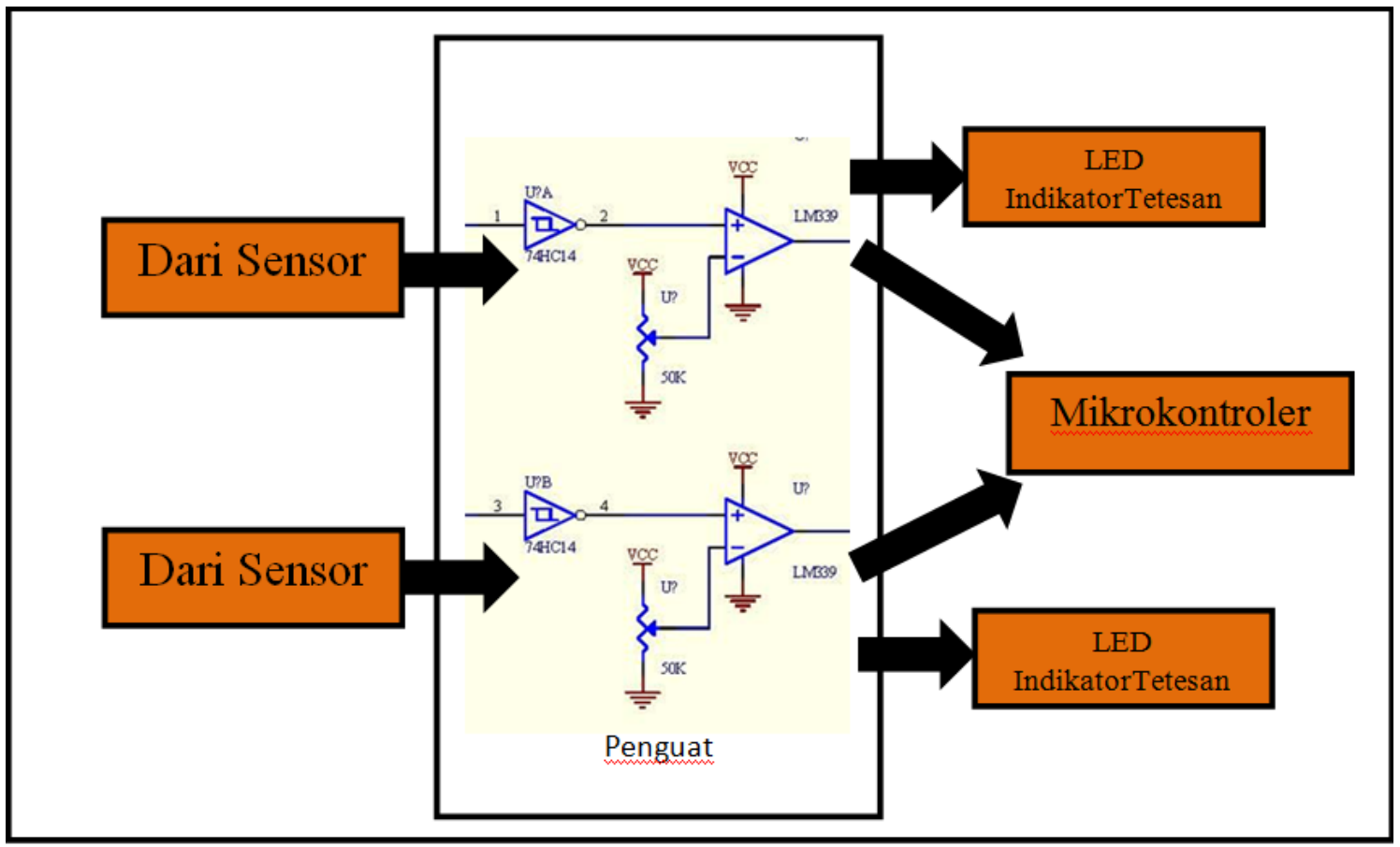

Gambar 3. Skematik Rangkaian Komparator

Pengondisi sinyal yang digunakan pada alat ini adalah komparator yang sudah terintegrasi pada chip IC. IC komparator yang digunakan adalah LM339. LM339 memiliki 4 buah op-amp komparator yang dapat membandingkan antar 2 sinyal input tegangan yaitu V- dan V+ yang salah satunya diatur sebagai $\mathrm{V}$ referensi. Pada bagian sensor tetesan, $\mathrm{V}$ - digunakan sebagai masukan dari nilai tegangan dari rangkaian infra merah dan photodioda, dan $\mathrm{V}+$ adalah tegangan referensi sebagai pembanding dari nilai V-. Agar masukan Vref dapat diatur maka digunakan sebuah trimpot yang tegangannya didapat dari Vcc yaitu sebesar $5 \mathrm{~V}$.

Untuk sensor tetesan digunakan 2 buah Op-Amp, masing-masing berfungsi sebagai keluaran langsung ke LED dan sebagai masukan dari mikrokontroler. Maka dari itu masukan Vdigunakan sebagai Vref dan V+ digunakan sebagai keluaran dari rangkaian sensor infra red dan photodioda. Output dari Op-Amp tersebut dihubungkan juga dengan mikrokontroler untuk dilakukan pengolahan data.

\section{Rangkaian Pengendali}

Pada rangkaian pengendali ini digunakan chip IC mikrokontroler sebagai pengolah data dari informasi yang didapat dari masukan keseluruhan sistem seperti komparator dan keypad. ATmega8535 digunakan sebagai penghitung logik yang didapat dari komparator dan input dari keypad sehingga tombol-tombol dari keypad dapat langsung berinteraksi dengan komponen penampil seperti LCD. Data yang telah diolah oleh mikrokontroler dikeluarkan pada perangkat keluaran yaitu LED, LCD dan buzzer. Dapat dilihat pada Gambar 4. 


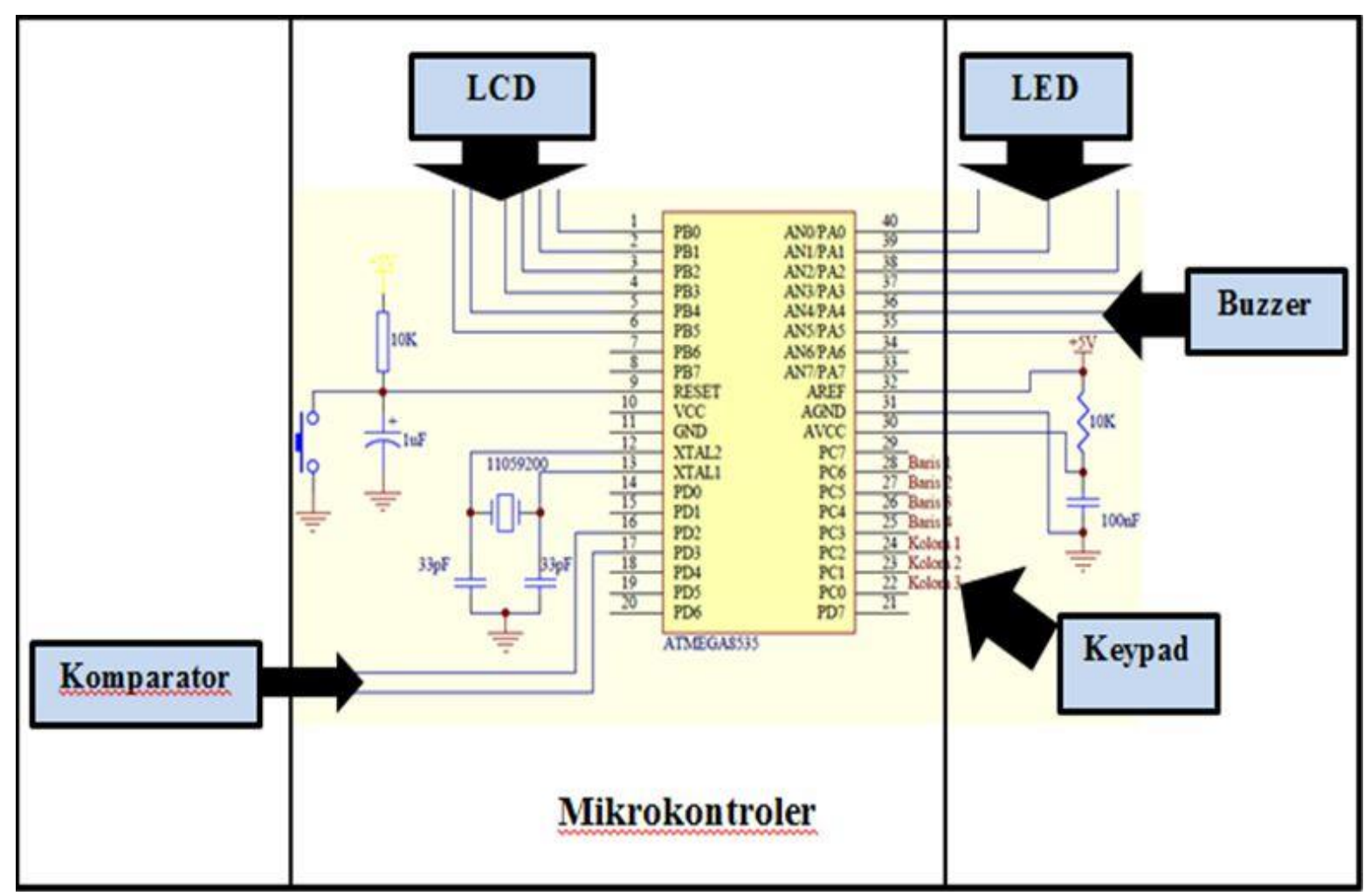

Gambar 4. Skematik Rangkaian Mikrokontroler

\section{Rangkaian Driver LCD}

Agar mikrokontroler dapat langsung terhubung dengan port - port dari LCD maka diperlukan sebuah rangkaian driver sehingga dapat langsung berkomunikasi satu sama lain.

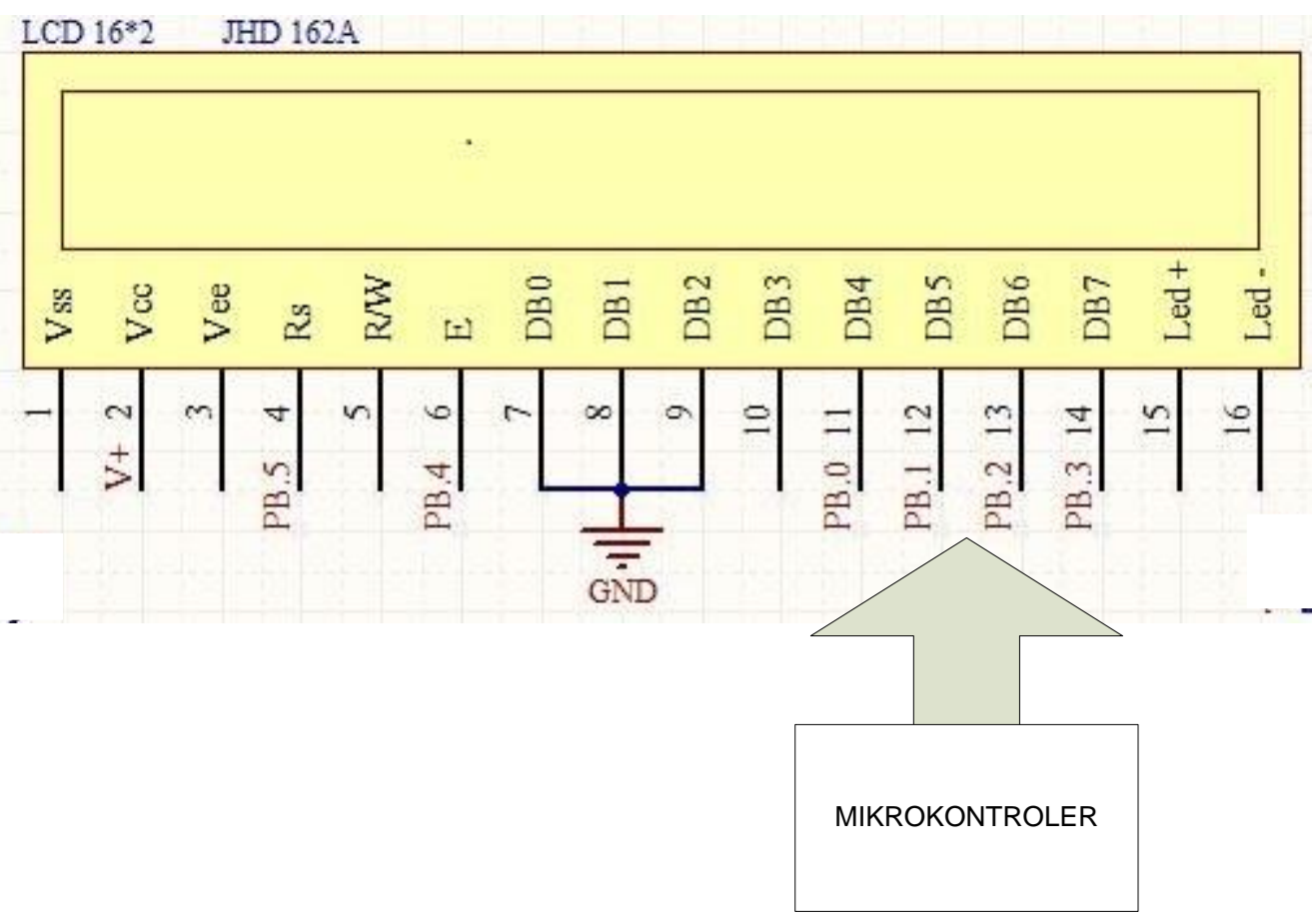

Gambar 5. Skematik Rangkaian Liquid Crystal Display (LCD) 


\subsection{Realisasi Mekanik Infus}

Agar alat ini dapat digunakan sesuai dengan fungsinya maka ada beberapa hal yang harus dipertimbangkan dalam perancangan chasis, diantaranya :

\subsubsection{Tiang infus}

Tiang infus yang biasa digunakan di rumah sakit sebenarnya dapat digunakan untuk alat ini selama tiang tersebut dapat menopang box infus dengan baik. Ketinggian dari tiang infus pun perlu dipertimbangkan yaitu botol infus diusahakan berada pada ketinggian $\pm 170 \mathrm{~cm}$.

Gambar 6 menunjukkan perancangan tiang dan infus pada alat Monitoring Infus Set pada pasien rawat inap.

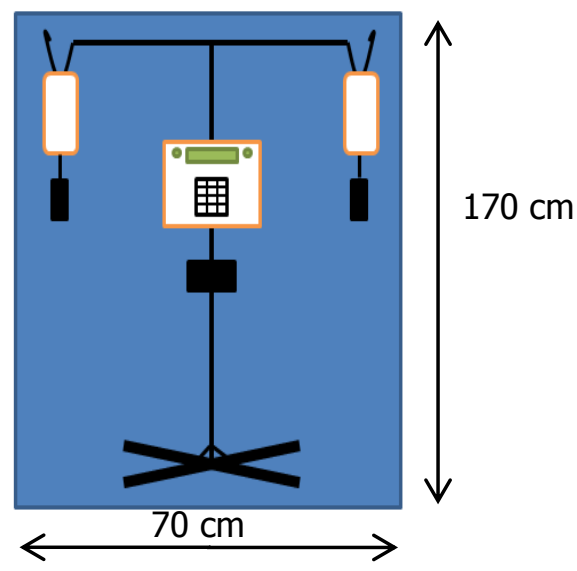

\section{Gambar 6. Perancangan Tiang dan Chasis Alat Monitoring Infus Set}

\subsubsection{Dudukan pendeteksi tetesan}

Dikarenakan alat ini mendeteksi tetesan yang terdapat pada chamber/tabung tetesan maka posisi pancaran cahaya infra merah harus tepat mengenai ke arah turunnya tetesan yaitu tepat ditengah tabung tetesan. Sehingga LED Infra merah, tetesan dan photodioda dirancang sedemikian rupa sehingga terdapat pada satu garis lurus. Maka dari itu dirancang sebuah dudukan tabung tetesan dan selang infus agar sensor cahaya dapat tepat mendeteksi objek yang dideteksi yaitu tetesan. Untuk lebih jelasnya dapat dilihat pada Gambar 7 dan Gambar 8.



Gambar 7. Posisi Sensor Pendeteksi Tetesan Pada Dudukan Chamber Infus 


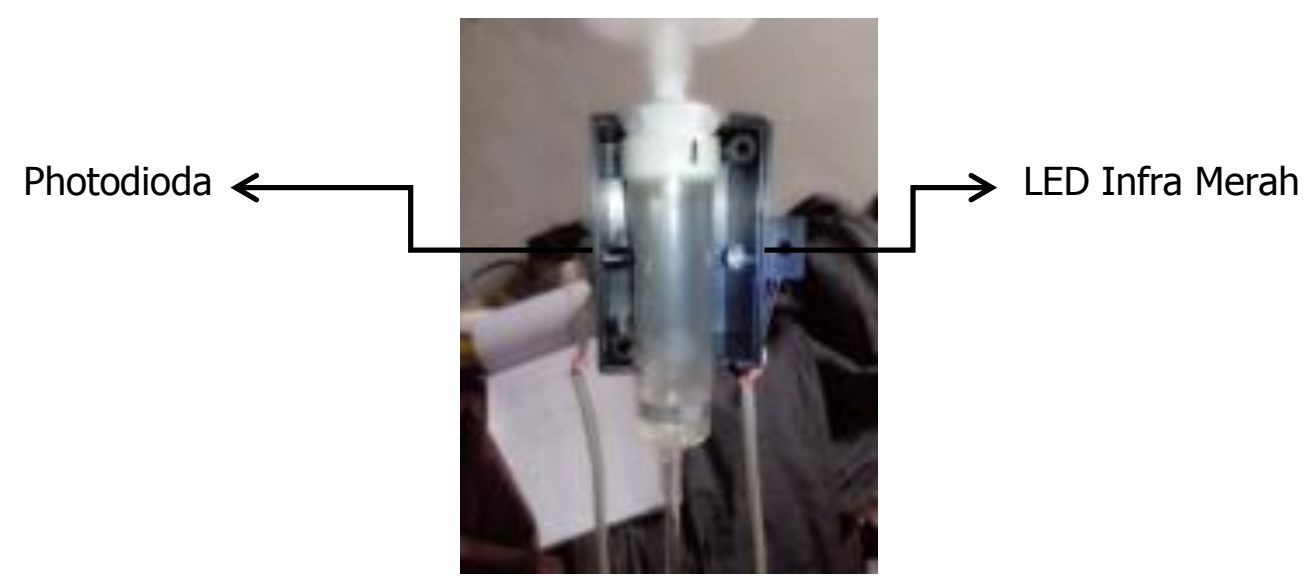

Gambar 8. Foto Letak Sensor Optik (Pendeteksi Tetesan) pada Chamber

\subsubsection{Peletakan Keypad, LCD, dan LED Indikator}

Untuk memudahkan perawat dalam mengoperasikan alat ini maka LCD dan keypad harus diletakan berdekatan. Selain itu LED Indikator mempunyai warna yang berbeda dengan indikasi yang berbeda sehingga dapat diketahui dengan mudah. Gambar 9 menunjukan bentuk chasis secara keseluruhan.

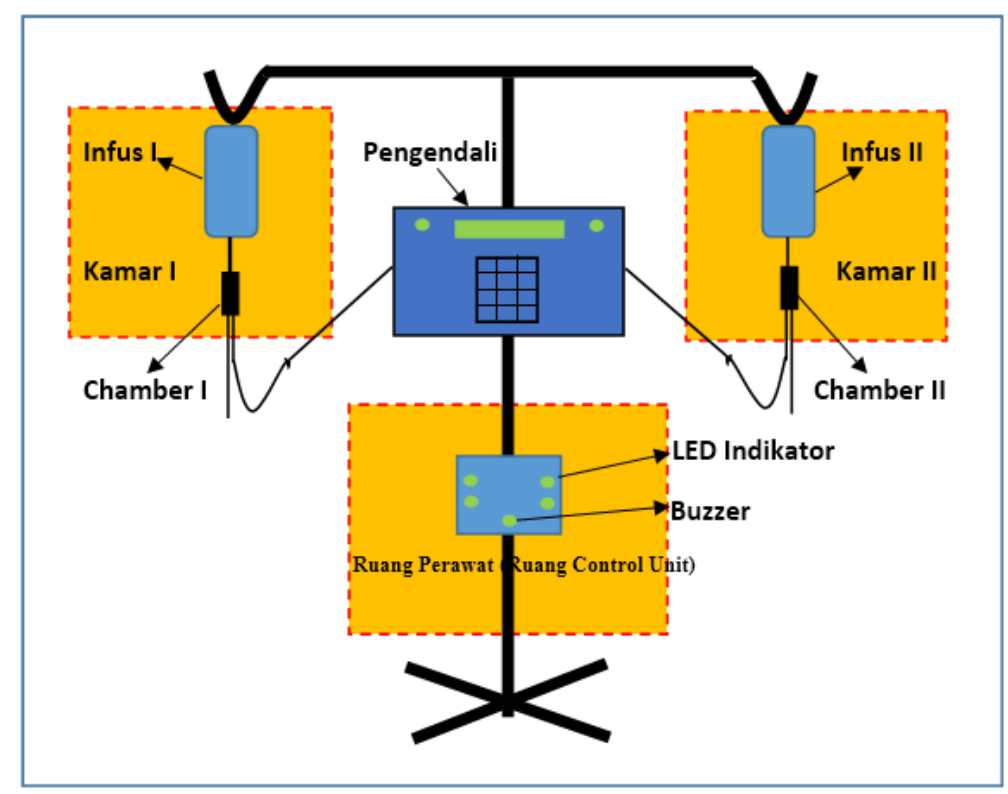

Gambar 9. Bentuk Chasis Box Alat Monitoring Infus Set Secara Keseluruhan

\subsection{Perancangan dan Realisasi Perangkat Lunak}

Spesifikasi perangkat lunak yang dirancang adalah:

1. Perancangan dan realisasi perangkat lunak menggunakan bahasa basic compiler dengan software Bascom AVR.

2. Perangkat lunak yang direalisasikan dengan menggunakan sensor optik (pendeteksi tetesan) LED infra merah dan photodioda, pengondisi sinyal LM339, keypad, display LCD dengan mikrokontroler.

3. Perangkat lunak dirancang dan direalisasikan untuk mendeteksi tetesan pada chamber. Masukkan data volume infus melalui keypad lalu ditampilkan pada LCD berupa jumlah tetesan sebenarnya secara real time. Jika tidak ada tetesan pada chamber maka LED 
warna hijau padam dan buzzer menyala dengan delay waktu 10 detik. Jika cairan infus sisa $50 \mathrm{ml}$ maka LED warna kuning padam dan buzzer menyala.

4. Proses download kode program ke flash PEROM mikrokontroler dilakukan dengan menggunakan ISP-Flash Programmer 3.0a.

Pada perancangan perangkat lunak digunakan Basic Compiler (BASCOM). Sebelum membuat program maka terlebih dahulu dibuat diagram alir keseluruhan sistem. Berikut pada Gambar 11 dan 12 diagram alir dari program yang akan dirancang.

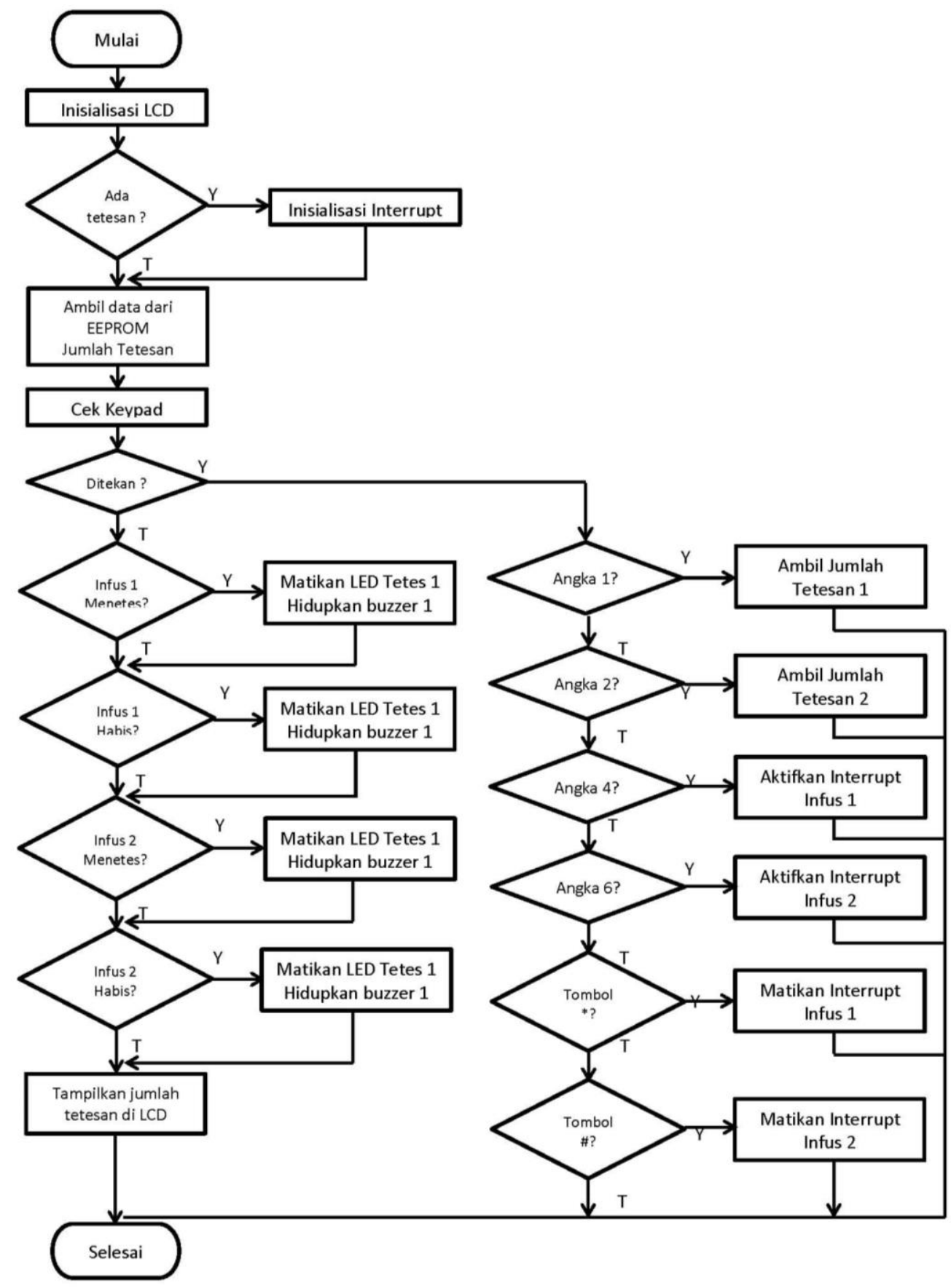

Gambar 11. Diagram Alir Alat Monitoring Infus Set pada Pasien Rawat Inap 

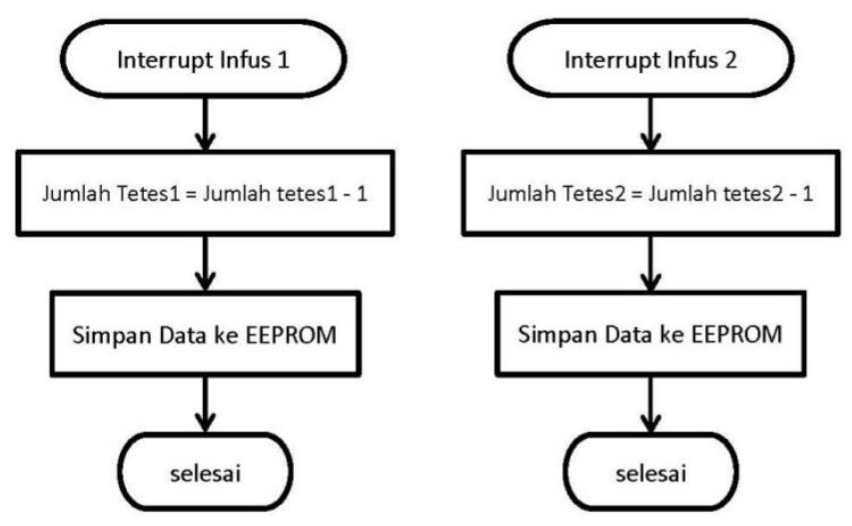

Gambar 12. Diagram Alir Inisialisasi Interrupt Infus

\section{PENGUJIAN SISTEM}

Pengujian sistem secara keseluruhan, dilakukan dengan cara mengintegrasikan seluruh subsistem perangkat keras (hardware) dan perangkat lunak (software), tujuan dari pengujian sistem secara terintegrasi adalah untuk mengetahui apakah sistem yang dirancang sudah dapat bekerja atau belum.

Untuk menguji bahwa seluruh blok rangkaian dapat berfungsi dengan baik maka alat harus langsung diaplikasikan menggunakan infus set yang biasa digunakan oleh pasien rumah sakit. Pengujian dilakukan dengan cara mensimulasikan alat Monitoring Infus Set sesuai dengan prosedur penggunaan infus set yang dilakukan oleh perawat.

\subsection{Pengujian Pendeteksi Tetesan Infus}

Pendeteksi tetesan pada alat ini ada 2 (dua) yaitu pendeteksi tetesan pada infus I dan pendeteksi tetesan pada infus II. Maka dari itu dilakukan pengujian pada infus I dan infus II yaitu :

\section{Pendeteksi tetesan pada infus 1}

Buka perlahan pengaturan tetesan sehingga terlihat ada cairan infus yang menetes. Untuk mengecek apakah sensor infra merah mendeteksi tetesan, perhatikan LED Indikator tetesan. Tiap ada cairan yang menetes maka LED menyala, dan begitu seterusnya. Dapat dilihat pada Tabel 1.

Tabel 1. Hasil Pengujian Sensor Pendeteksi Tetesan Infus I

\begin{tabular}{|c|c|c|c|}
\hline No. & $\begin{array}{c}\text { Vo Pendeteksi } \\
\text { Tetesan (Volt) }\end{array}$ & Status Tetesan & $\begin{array}{c}\text { Kondisi LED Indikator } \\
\text { Tetesan }\end{array}$ \\
\hline 1. & 1,04 & Menetes & kedip \\
\hline 2. & 1,01 & Menetes & kedip \\
\hline 3. & 1,06 & Menetes & kedip \\
\hline 4. & 1,02 & Menetes & kedip \\
\hline 5. & 1,02 & Menetes & kedip \\
\hline 6. & 1,10 & Menetes & kedip \\
\hline 7. & 1,01 & Menetes & kedip \\
\hline 8. & 1,02 & Menetes & kedip \\
\hline 9. & 1,03 & Menetes & kedip \\
\hline 10. & 1,02 & Menetes & \\
\hline Nilai rata-rata $(\boldsymbol{x})$ & 1,03 & &
\end{tabular}


Pada hasil pengujian Tabel 1. terdapat perbedaan nilai output saat pengujian Vo pendeteksi tetesan maka dari itu dilakukan 10 (sepuluh) kali pengujian. Perbedaan nilai yang terbaca terjadi karena ukuran skala dan jarum yang kecil dan juga kesalahan sudut pandang mata. Namun perbedaan yang terjadi memanglah tidak signifikan, hal ini terjadi karena keakuratan alat (multimeter analog) dan juga kalibrasi alat (multimeter analog) sebelum pengukuran dilakukan. Dari 10 (sepuluh) kali pengujian, nilai rata-rata ( $\boldsymbol{x}$ ) untuk Vo pendeteksi tetesan saat mendeteksi adanya tetesan adalah 1,03 volt. Saat nilai output pendeteksi tetesan 1,03 volt, kondisi LED indikator tetesan "kedip". Hasil pengujian ini pun membuktikan bahwa LED indikator tetesan berfungsi dengan baik.

\section{Pendeteksi tetesan pada infus II}

Buka perlahan pengaturan tetesan sehingga terlihat ada cairan infus yang menetes. Untuk mengecek apakah sensor infra merah mendeteksi tetesan, perhatikan LED Indikator tetesan. Tiap ada cairan yang menetes maka LED menyala, dan begitu seterusnya. Dapat dilihat pada Tabel 2.

Tabel 2. Hasil Pengujian Sensor Pendeteksi Tetesan Infus II

\begin{tabular}{|c|c|c|c|}
\hline No. & $\begin{array}{c}\text { Vo Pendeteksi } \\
\text { Tetesan (Volt) }\end{array}$ & Status Tetesan & $\begin{array}{c}\text { Kondisi LED Indikator } \\
\text { Tetesan }\end{array}$ \\
\hline 1. & 1,07 & Menetes & kedip \\
\hline 2. & 1,02 & Menetes & kedip \\
\hline 3. & 1,02 & Menetes & kedip \\
\hline 4. & 1,03 & Menetes & kedip \\
\hline 5. & 1,01 & Menetes & kedip \\
\hline 6. & 1,00 & Menetes & kedip \\
\hline 7. & 1,01 & Menetes & kedip \\
\hline 8. & 1,02 & Menetes & kedip \\
\hline 9. & 1,04 & Menetes & kedip \\
\hline 10. & 1,10 & Menetes & kedip \\
\hline Nilai rata-rata $(\boldsymbol{x})$ & 1,03 & & \\
\hline
\end{tabular}

Pada hasil pengujian Tabel 2. terdapat perbedaan nilai output saat pengujian Vo pendeteksi tetesan maka dari itu dilakukan 10 (sepuluh) kali pengujian. Perbedaan nilai yang terbaca terjadi karena ukuran skala dan jarum yang kecil dan juga kesalahan sudut pandang mata. Namun perbedaan yang terjadi memanglah tidak signifikan, hal ini terjadi karena keakuratan alat (multimeter analog) dan juga kalibrasi alat (multimeter analog) sebelum pengukuran dilakukan. Dari 10 (sepuluh) kali pengujian, nilai rata-rata ( $\boldsymbol{x}$ ) untuk Vo pendeteksi tetesan saat mendeteksi adanya tetesan adalah 1,03 volt. Saat nilai output pendeteksi tetesan 1,03 volt, kondisi LED indikator tetesan "kedip". Hasil pengujian ini pun membuktikan bahwa LED indikator tetesan berfungsi dengan baik.

\subsection{Pengujian Pendeteksi "Blood Rejection"/ Tetesan Terhenti}

Untuk menguji peringatan bila tetesan tidak terdeteksi selama 10 detik dapat dilakukan dengan memastikan bahwa tetesan telah terdeteksi oleh sensor infra merah dengan melihat LED indikator tetesan dan menutup pengaturan tetesan sehingga tidak terdapat tetesan yang keluar di dalam chamber. Hasil pengujiannya dapat dilihat pada Tabel 3. 
Tabel 3. Hasil Pengujian Saat Tidak Ada Tetesan

\begin{tabular}{|c|c|c|c|}
\hline No. & $\begin{array}{c}\text { Vo Pendeteksi } \\
\text { Tetesan }(\mathrm{V})\end{array}$ & Status Tetesan & $\begin{array}{c}\text { Kondisi LED Indikator } \\
\text { Tetesan }\end{array}$ \\
\hline 1. & 0,178 & Tidak Menetes & Padam \\
\hline 2. & 0,179 & Tidak Menetes & Padam \\
\hline 3. & 0,180 & Tidak Menetes & Padam \\
\hline 4. & 0,180 & Tidak Menetes & Padam \\
\hline 5. & 0,176 & Tidak Menetes & Padam \\
\hline 6. & 0,182 & Tidak Menetes & Padam \\
\hline 7. & 0,181 & Tidak Menetes & Padam \\
\hline 8. & 0,180 & Tidak Menetes & Padam \\
\hline 9. & 0,179 & Tidak Menetes & Padam \\
\hline 10. & 0,180 & Tidak Menetes & Padam \\
\hline Nilai rata-rata $(\boldsymbol{x})$ & 0,179 & & \\
\hline
\end{tabular}

Pada hasil pengujian Tabel 3., terdapat perbedaan nilai output saat pengujian Vo pendeteksi tetesan maka dari itu dilakukan 10 (sepuluh) kali pengujian. Perbedaan nilai yang terbaca terjadi karena ukuran skala dan jarum yang kecil dan juga kesalahan sudut pandang mata. Namun perbedaan yang terjadi memanglah tidak signifikan, hal ini dikarenakan keakuratan alat (multimeter analog) dan juga kalibrasi alat (multimeter analog) sebelum pengukuran dilakukan. Dari 10 (sepuluh) kali pengujian, nilai rata-rata ( $\boldsymbol{x}$ ) untuk Vo pendeteksi tetesan saat mendeteksi adanya tetesan adalah 0,179 V. Saat nilai output pendeteksi tetesan 0,179 $\mathrm{V}$, kondisi LED indikator tetesan "padam". Hasil pengujian ini pun sesuai dengan tujuan awal dari alat yang dirancang karena pengujian ini membuktikanalat Monitoring Infus Set mendeteksi saat tidak adanya tetesan pada chamber berfungsi dengan baik.

Setelah menutup pengaturan tetesan sehingga tidak tetesan yang keluar dari chamber, tunggu hingga 10 detik maka LED warna hijau padam dan buzzer menyala. Hasil pengujiannya dapat dilihat pada Tabel 4.

Tabel 4. Hasil Pengujian Pada Saat Tetesan Terhenti

\begin{tabular}{|c|c|c|c|c|}
\hline Waktu (detik) & $\begin{array}{c}\text { Vo Pendeteksi } \\
\text { Tetesan }(\text { V) }\end{array}$ & $\begin{array}{c}\text { Kondisi LED } \\
\text { warna Hijau }\end{array}$ & $\begin{array}{c}\text { Status } \\
\text { Tetesan }\end{array}$ & $\begin{array}{c}\text { Kondisi } \\
\text { Buzzer }\end{array}$ \\
\hline 1 & 0,180 & Nyala & Tidak Menetes & Padam \\
\hline 2 & 0,183 & Nyala & Tidak Menetes & Padam \\
\hline 3 & 0,182 & Nyala & Tidak Menetes & Padam \\
\hline 4 & 0,177 & Nyala & Tidak Menetes & Padam \\
\hline 5 & 0,178 & Nyala & Tidak Menetes & Padam \\
\hline 6 & 0,180 & Nyala & Tidak Menetes & Padam \\
\hline 7 & 0,181 & Nyala & Tidak Menetes & Padam \\
\hline 8 & 0,179 & Nyala & Tidak Menetes & Padam \\
\hline 9 & 0,180 & Nyala & Tidak Menetes & Padam \\
\hline 10 & 0,181 & Padam & Tidak Menetes & Nyala \\
\hline Nilai rata-rata $(\boldsymbol{x})$ & 0,180 & & & \\
\hline
\end{tabular}

Pada hasil pengujian Tabel 4. dilakukan berdasarkan sample waktu. Terdapat perbedaan nilai output saat pengujian Vo pendeteksi tetesan maka dari itu dilakukan 10 (sepuluh) kali pengujian. Perbedaan nilai yang terbaca terjadi karena ukuran skala dan jarum yang kecil dan juga kesalahan sudut pandang mata. Namun perbedaan yang terjadi memanglah tidak signifikan, hal ini dikarenakan keakuratan alat (multimeter analog) dan juga kalibrasi alat (multimeter analog) sebelum pengukuran dilakukan. Terdapat 10 data yang diujikan pada Tabel 4. Pada saat detik ke-1 hingga detik ke-9, kondisi LED warna hijau menyala dan kondisi buzzer masih mati, lalu saat detik ke-10 kondisi LED warna hijau pun mati dan 
kondisi buzzer menyala. Hasil pengujian ini pun sesuai dengan program yang dibuat yang terdapat pada mikrokontroler, karena pada program mikrokontroler dibuat selama 10 detik saat mendeteksi tetesan terhenti.

\subsection{Pengujian Peringatan Infus Akan Habis}

Pada alat Monitoring Infus Set ini hanya menampilkan jumlah tetesan sebenarnya secara real time pada LCD. Untuk volume infus yang $500 \mathrm{ml}$, jumlah tetesannya sebanyak 7500 tetesan. Jumlah tetesan tersebut didapat dengan memasukkan formulasi :

$$
\text { Jumlah tetesan }=\text { Volume cairan infus } \mathrm{x} \text { Jenis chamber yang digunakan }
$$

Dapat dilihat pada Tabel 5. data perhitungan jumlah tetesan.

Tabel 5. Data Perhitungan Jumlah Tetesan

\begin{tabular}{|c|c|c|}
\hline Volume cairan infus $(\mathrm{ml})$ & Jenis Chamber (tetes/ml) & Jumlah tetesan \\
\hline 500 & 15 & 7500 \\
\hline 450 & 15 & 6750 \\
\hline 400 & 15 & 6000 \\
\hline 350 & 15 & 5250 \\
\hline 300 & 15 & 4500 \\
\hline 250 & 15 & 3750 \\
\hline 200 & 15 & 3000 \\
\hline 150 & 15 & 2250 \\
\hline 100 & 15 & 1500 \\
\hline 50 & 15 & 750 \\
\hline
\end{tabular}

Penentuan peringatan cairan infus akan habis dengan cairan infus sisa $\pm 50 \mathrm{ml}$ dimaksudkan agar perawat memiliki waktu lebih dalam mengganti cairan infus di ruangan pasien rawat inap. Untuk menguji peringatan bila cairan infus akan habis / kira - kira tersisa $\pm 50 \mathrm{ml}$ dapat dilakukan dengan memasukkan volume infus sebesar $500 \mathrm{ml}$ melalui keypad dan tampilan pada LCD menunjukkan 7500 tetesan. Buka pengaturan tetesan dan tampilan pada LCD memulai perhitungan mundur tetesan, dari 7500 tetesan hingga menuju 750 tetesan sesuai dengan hasil pada Tabel 5 . Hasil pengujian cairan infus akan habis $( \pm 50 \mathrm{ml})$ dapat dilihat pada Tabel 6.

Tabel 6. Hasil Pengujian Cairan Infus Akan Habis $( \pm \mathbf{5 0} \mathbf{~ m l})$

\begin{tabular}{|c|c|c|c|c|}
\hline $\begin{array}{c}\text { Jumlah Tetesan } \\
\text { pada LCD }\end{array}$ & $\begin{array}{c}\text { Vo Pendeteksi } \\
\text { Tetesan }(\mathrm{V})\end{array}$ & $\begin{array}{c}\text { Kondisi LED } \\
\text { warna Kuning }\end{array}$ & $\begin{array}{c}\text { Status } \\
\text { Tetesan }\end{array}$ & Kondisi Buzzer \\
\hline 7500 & 1,02 & Nyala & Menetes & Padam \\
\hline 6750 & 1,01 & Nyala & Menetes & Padam \\
\hline 6000 & 1,05 & Nyala & Menetes & Padam \\
\hline 5250 & 1,02 & Nyala & Menetes & Padam \\
\hline 4500 & 1,01 & Nyala & Menetes & Padam \\
\hline 3750 & 1,05 & Nyala & Menetes & Padam \\
\hline 3000 & 1,07 & Nyala & Menetes & Padam \\
\hline 2250 & 1,02 & Nyala & Menetes & Padam \\
\hline 1500 & 1,02 & Nyala & Menetes & Padam \\
\hline 750 & 0,180 & Padam & Tidak Menetes & Nyala \\
\hline
\end{tabular}

Pada hasil pengujian Tabel 6. dilakukan berdasarkan jumlah tetesan yang ditampilkan pada LCD. Terdapat 10 data yang diujikan pada Tabel 6. Pada saat jumlah tetesan yang ditampilkan pada LCD menghitung mundur dari 7500 tetesan hingga 1500 tetesan, kondisi LED warna kuning menyala dan kondisi buzzer masih padam, lalu saat jumlah tetesan pada 
LCD sebanyak 750 tetesan ( cairan infus $50 \mathrm{ml}$ ) maka kondisi LED warna kuning pun mati dan kondisi buzzer menyala. Hasil pengujian ini pun sesuai dengan program yang dibuat yang terdapat pada mikrokontroler dan juga tujuan awal dari alat yang dirancang.

\subsection{Pengujian Respon Tetesan}

Pengujian ini dilakukan dengan tujuan untuk menghitung jumlah tetesan secara tepat dengan cara membandingkan jumlah tetesan yang dikeluarkan chamber dari hasil perhitungan manual dengan jumlah tetesan dari hasil perhitungan sistem mikrokontroler yang ditampilkan pada LCD. Hasil pengujian respon tetesan dapat dilihat pada Tabel 7.

Tabel 7. Data Pengujian Respon Tetesan

\begin{tabular}{|c|c|c|}
\hline $\begin{array}{c}\text { Volume cairan infus yang dikeluarkan } \\
\text { dalam 1 menit (ml) }\end{array}$ & $\begin{array}{c}\text { Hasil Perhitungan } \\
\text { Secara Manual }\end{array}$ & $\begin{array}{c}\text { Hasil Perhitungan yang } \\
\text { Ditampilkan pada LCD }\end{array}$ \\
\hline 1 & 15 & 15 \\
\hline 2 & 30 & 30 \\
\hline 3 & 45 & 45 \\
\hline 4 & 60 & 60 \\
\hline 5 & 75 & 75 \\
\hline 6 & 90 & 90 \\
\hline 7 & 105 & 105 \\
\hline 8 & 120 & 120 \\
\hline 9 & 135 & 135 \\
\hline 10 & 150 & 150 \\
\hline 15 & 225 & 225 \\
\hline 17 & 255 & 255 \\
\hline
\end{tabular}

Pada Tabel 7, data yang diambil adalah jumlah volume cairan infus maksimum yang dikeluarkan selama \pm 1 menit. Jumlah volume cairan infus maksimumnya adalah $17 \mathrm{ml}$ dengan perincian yang dapat dilihat pada Tabel 7. Dapat dilihat bahwa jumlah tetesan dari hasil perhitungan secara manual adalah sama dengan jumlah tetesan dari hasil perhitungan yang ditampilkan pada LCD maka pengujian akurasi sensor infra merah dalam mendeteksi tetesan membuktikan bahwa alat ini dapat memonitor banyaknya tetesan dengan tepat.

\subsection{Pengujian Buzzer}

Pada perangkat keluaran/output terdapat buzzer yang berfungsi untuk memberikan informasi berupa bunyi ketika tidak adanya tetesan pada chamber dan cairan infus akan habis (sisa $\pm 50 \mathrm{ml}$ ). Pengujian pada buzzer dengan mengukur tingkat kebisingan buzzer menggunakan Sound Level Meter (SLM) lebih besar daripada tingkat kebisingan di rumah sakit sehingga penggunaan buzzer pada alat Monitoring Infus Set sangat efektif. Meskipun keadaan di ruangan perawat sangat ramai akan tetapi suara buzzer masih terdengar.

\section{KESIMPULAN}

Setelah melakukan pengujian dan analisa pada seluruh blok rangkaian, dapat disimpulkan bahwa :

1. Agar tetesan dapat dideteksi oleh sensor infra merah maka pemancar, penerima, dan chamber harus ditempatkan dalam satu garis lurus

2. Sensor infra merah dengan menggunakan photodioda dapat mendeteksi adanya tetesan pada chamber ruang tetesan infus karena responsibilitas photodioda dalam mendeteksi cahaya infra merah lebih baik dibandingkan phototransistor.

3. Sensor Infra merah dapat mendeteksi tetesan cairan infus dengan melihat adanya perbedaan tegangan output sensor pada saat dilewati tetesan dan tidak dilewati tetesan. 
Pada saat dilewati tetesan tegangan output yang dihasilkan adalah sebesar $1,02 \mathrm{~V}$, sedangkan saat sensor tidak dilalui tetesan tegangan output yang dihasilkan adalah sebesar $180 \mathrm{mV}$.

4. Alat monitoring infus yang telah direalisasikan dapat memenuhi spesifikasi yang diharapkan yaitu alat dapat mendeteksi tetesan dan menampilkan jumlah tetesan sebenarnya secara real time pada LCD secara terus-menerus sehingga kecepatan tetesan dapat dimonitor dengan baik. Maksimal kecepatan tetesan yang dapat terdeteksi adalah \pm 255 tetes / menit sedangkan kecepatan tetesan paling cepat pada penggunaan infus intravena adalah sebesar 125 tetes/menit yaitu ketika cairan infus harus habis dalam waktu 1 jam. Dengan demikian alat ini dapat memenuhi kecepatan tetesan untuk pemberian cairan infus paling cepat yaitu dalam waktu 1 jam.

5. Alat Monitoring Infus Set ini direalisasikan sebanyak dua unit untuk memperlihatkan bahwa alat ini dapat digunakan untuk dua orang pasien rawat inap dan diaplikasikan pada ruangan pasien rawat inap.

6. Suara yang dihasilkan buzzer masih terdengar jelas dengan nilai tingkat kebisingan sebesar $73 \mathrm{~dB}$ dan tidak berbahaya bagi pendengaran perawat berdasarkan nilai ambang tingkat kebisingan meskipun keadaan di ruangan perawat dalam kondisi ramai.

\section{DAFTAR RUJUKAN}

Boylestad, Robert. L ;Nashelky, Louis.(2001). Electronic Devices and Circuit Theory. New Jersey : Prentice Hall Inc.

Wahyudin, Didin.(2008). Belajar Mudah Dengan Bahasa Basic Menggunakan Bascom-8051 Untuk Mikrokontroler Atmega8535. Yogyakarta : ANDI.

Falat, Jati.(2006). Realisasi Monitoring Level Cairan Infus Pada Pasien Rawat Inap Berbasis $P C$. Bandung : Politeknik Negeri Bandung.

Tim Poskota. (2011). Seorang Bayi Meninggal Dikarenakan Perawat Terlambat Mengganti Cairan Infus. Dipetik pada 6 Mei 2014 dari http://www.poskota.co.id/berita-terkini

Tim Lab Mikroprossesor Elektronika.(2006). Pemrograman Mikrokontroler AT89S51 dengan $\mathrm{C} / \mathrm{C}++$ dan Assembler. Yogyakarta : ANDI.

Saing, Iwan. (2008). Menghitung Tetesan Cairan Infus. Dipetik pada 6 Mei 2014 dari http://iwansaing.wordpress.com.

Futurlec. (2008). Keypad. Dipetik pada 6 Mei 2014 dari http://www.futurlec.com/Keypads.shtml.

Yono. (2011). Gambaran Penggunaan Jarum Infus dan Prosedurnya. Dipetik pada 6 Mei 2014 dari http://www.yonokomputer.com.

Muslim, Abdy. (2012). Monitoring Cairan Infus Menggunakan Modul Radio Frekuensi YS1020UB. Dipetik pada $10 \quad$ Juni 2014 dari www.elektro.undip.ac.id/el.../L2F309012_MTA.pdf.

Astuti, Annisa. D. (2012). Penggunaan Sistem Optocoupler pada Infusion Pump TE-112. Dipetik pada 10 Juni 2014 dari http://www.academia.edu/10658349 